\title{
Effect of extrusion conditions on the expansion of extruded apple pomace - wheat semolina mixtures
}

\author{
Milena Ruskova ${ }^{1}$, Todorka Petrova ${ }^{1}$, Nikolay Penov \\ 1 - Institute of Food Preservation and Quality, Plovdiv, Bulgaria \\ 2 - University of Food Technology, Plovdiv, Bulgaria
}

\begin{abstract}
Apple pomace - wheat semolina mixtures were extruded in a laboratory single screw extruder (Brabender 20 DN, Germany) with screw diameter $19 \mathrm{~mm}$ and die diameter $5 \mathrm{~mm}$. Effects of apple pomace content in the mixtures, moisture content, screw speed, and barrel temperature on the expansion of the extruded products were studied. Response surface methodology with combinations of apple pomace content in the mixtures $(10,30,50,70,90 \%)$, moisture content $(17,20,23,26,29 \%)$, screw speed $(120,150,180,210,240 \mathrm{rpm})$, and barrel temperature $(130,140,150,160$, $170^{\circ} \mathrm{C}$ ) was applied. Feed screw speed was fixed at $70 \mathrm{rpm}$. The compression ratio of the screw was 3:1. The temperatures of the feed and kneading zone were 150 and $160^{\circ} \mathrm{C}$, respectively. Sectional expansion index $(S E I)$, the ratio of diameter of extrudate and the diameter of die, was used to express the expansion of extrudate. The average $S E I$ values ranged from 0.827 to 1.637 . Statistical analysis showed that apple pomace content in the mixtures, moisture content, and barrel temperature had effect on $S E I$ while screw speed had not affect expansion index of the extrudates.
\end{abstract}

Key words: apple, pomace, wheat, semolina, extrusion.

Corresponding author: Milena Ruskova

E-mail: mmruskova@gmail.com

DOI: $10.24263 /$ RES-2019-3

\section{Introduction}

Apple pomace (AP) is the main by-product of cider processing and pose a serious environmental problem due to the large amounts produced every year. AP is composed mainly of carbohydrates and dietary fibre, small amounts of protein, fat and ash [1]. AP is a good source of phytochemicals primarily phenolic acids and flavonoids [2].

The common applications of this by-product are the direct disposal to soil in a landfill and for pectin recovery usage. In recent years, investigations into the incorporation of apple pomace in foods especially in baked foods [1].

Extruded snack products made predominantly from cereal flour tend to be low in protein with low biological value. The incorporation of enriched fibre flours with significant values of antioxidants is a way to improve the nutritional value of these 
snacks. Apple pomace rich in fibre with significant amounts of antioxidants can be incorporated in human food-chain thus generating new potential functional foods.

Extrudate expansion is a complex phenomenon which occurs usually during hightemperature, low-moisture extrusion cooking. Most extruded foods are actually made out of complex formulations which have different effects on the expansion [3]. Processing conditions and equipment-related variables also have the ability to influence the degree of expansion significantly.

The quality of the end product depends upon how the thermal performance of the extruder is controlled and what the thermomechanical history of the product is inside the extruder [4].

The object of this work was to study the effect of extrusion conditions on the expansion of extruded apple pomace - wheat semolina mixtures.

\section{Materials and methods}

Apple pomace is a by-product obtained during juice processing. Commercial apples (Granny Smith variety) were refrigerated and stored until the juice processing. The apple pomaces were dried a laboratory heat dryer at $60^{\circ} \mathrm{C}$. The dried pomaces were ground using a hammer mill then mixed with commercial wheat semolina and distilled water to be obtained the desired ratios (Table 1). The prepared wet samples were extruded in a laboratory single screw extruder (Brabender $20 \mathrm{DN}$, Germany). The feed screw speed was fixed at $70 \mathrm{rpm}$. The screw speed was according to the experimental design (Table 1). The compression ratio of the screw was 3:1. The temperatures of the feed and kneading zone were 150 and $160^{\circ} \mathrm{C}$, respectively. The temperature of the final cooking zone was $130,140,150,160,170^{\circ} \mathrm{C}$. The die diameter was $5 \mathrm{~mm}$.

Sectional expansion index ( $S E I)$, the ratio of diameter of extrudate and the diameter of die was used to express the expansion of extrudate [5,6]. The diameter of the extrudate was determined as the mean of 10 random measurements. The extrudate expansion index was calculated as

$$
S E I=\frac{D_{e}}{D_{d}}
$$

where $D e$ and $D d$ were diameter of the cooled extrudate and diameter of the die, respectively.

The effects of four independent extrusion parameters (variables) apple pomace content $\left(X_{1}\right)$, moisture content $\left(X_{2}\right)$, screw speed $\left(X_{3}\right)$, and barrel temperature $\left(X_{4}\right)$ on the dependent variable ( $S E I$ ) were investigated using central composite rotatable design [5] and response surface methodology (RSM). All variables were controlled at five different levels.

A second-order polynomial equation was used to fit the measured, dependent variable $(\mathrm{Y})$ as a function of the coded, independent extrusion variables $\left(\mathrm{X}_{\mathrm{i}}\right)$ :

$$
y=b_{0}+\sum_{i=1}^{n} b_{i} x_{i}+\sum_{i=1}^{n} b_{i i} x_{i}^{2}+\sum_{i=1}^{n} \sum_{j=1}^{n} b_{i j} x_{i} x_{j}
$$


where $b_{0}$ is the value for the fixed response at the central point of the experiment; and $b_{i}, b_{j}$ and $b_{i j}$ were the linear, quadratic and cross-product coefficients, respectively. The significance of the effect was given as a p-value. The effect was considered significant if the p-value for each factor or interaction is less than 0.05. SYSTAT statistical software (SPSS Inc., Chicago, USA, version 7.1) and Excel were used to analyze the data results.

\section{Results and discussion}

In extrusion cooking, expansion is the primary quality parameter associated with product crispiness, water absorption, and water solubility. During extrusion cooking of biopolymers, the viscoelastic material is forced through the die so that the sudden pressure drop causes part of the water vaporize, giving an expanded porous structure. Extruded products of different physical forms were obtained. The maximum and minimum values of $S E I$ of the extrudates were 1.637 and 0.827 , respectively (Table 1).

The results of the statistical analysis of variance (ANOVA) for SEI show that 4 effects have $\mathrm{p}$-values less than 0.05 , indicating that they are significantly different from zero at the $95.0 \%$ confidence level. The R-squared statistic is 0.93 ; the standard error of the estimate -8.44 , the mean absolute error -4.57 . The R-squared is defined as the ratio of the explained variation to the total variation and is a measure of the degree of fit [7]. As the R-squared value for the model is more than $80 \%$ it can be considered for further analysis.

The regression equation describing the effect of extrusion variables on SEI of extruded apple pomace - wheat semolina mixtures is given in Table 2 . The coefficients in the regression equation can be used to examine the significance of each term relative to each other when used with coded values. Statistical analysis showed that apple pomace content in the mixture, moisture content, and barrel temperature had an effect on $S E I$ ( $\mathrm{p}<0.05$ ), whereas screw speed had no effect on $S E I$.

Each of the estimated effects and interactions are shown in the standardized diagram (Figure 1). The linear effect due to apple pomace content in the mixture had mostly influence on SEI followed by linear effects due to the moisture content and barrel temperature. The apple pomace content in the mixture, moisture content and barrel temperature had negative effect on SEI. When the apple pomaces content increased from 10 to $90 \%$, the degree of expansion decreased almost twice (Table 1). Yagci \& Gogus [8]), Yanniotis et al. [9] reported that pectin-rich fruits have a negative effect on the radial expansion of extrudates which is consistent with this work.

The effect of changes in the moisture content and the barrel temperature on SEI of the samples is given in Figure 2. Simultaneously raising the barrel temperature and the moisture content leads to decreasing the degree of expansion. Increased feed moisture content during extrusion may reduce the elasticity of the dough through plasticization of the melt, resulting in reduced the specific mechanical energy and therefore reduced gelatinization, decreasing the expansion [10]. According to Kokini et al. [11], at $160^{\circ} \mathrm{C}$ 
and $26 \%$ moisture, expansion index decreased, probably because at high temperatures starch dextrinization occurred. Gujska and Khan [12] found a similar behaviour in navy bean extrudates. They also reported that screw speed did not affect expansion index which is consistent with this work.

Table 1

Central composite rotatable design in coded form and natural units of independent variables and experimental data for sectional expansion index

\begin{tabular}{|c|c|c|c|c|c|c|c|c|c|c|}
\hline \multirow{2}{*}{$\begin{array}{l}\text { Run } \\
\text { No }\end{array}$} & \multicolumn{4}{|c|}{$\begin{array}{l}\text { Independent variables } \\
\text { in coded form }\end{array}$} & \multicolumn{4}{|c|}{$\begin{array}{l}\text { Independent variables } \\
\text { in natural units }\end{array}$} & \multicolumn{2}{|c|}{ SEI (Y) } \\
\hline & $X_{1}$ & $X_{2}$ & $X_{3}$ & $X_{4}$ & $X_{1}$ & $X_{2}$ & $X_{3}$ & $X_{4}$ & $\begin{array}{l}\text { Experi- } \\
\text { mental }\end{array}$ & Predicted \\
\hline 1 & -1 & -1 & -1 & -1 & 30 & 20 & 150 & 140 & 1.637 & 1.630 \\
\hline 2 & +1 & -1 & -1 & -1 & 70 & 20 & 150 & 140 & 1.159 & 1.078 \\
\hline 3 & -1 & +1 & -1 & -1 & 30 & 26 & 150 & 140 & 1.362 & 1.373 \\
\hline 4 & +1 & +1 & -1 & -1 & 70 & 26 & 150 & 140 & 0.894 & 0.921 \\
\hline 5 & -1 & -1 & +1 & -1 & 30 & 20 & 210 & 140 & 1.552 & 1.566 \\
\hline 6 & +1 & -1 & +1 & -1 & 70 & 20 & 210 & 140 & 1.071 & 1.012 \\
\hline 7 & -1 & +1 & +1 & -1 & 30 & 26 & 210 & 140 & 1.583 & 1.471 \\
\hline 8 & +1 & +1 & +1 & -1 & 70 & 26 & 210 & 140 & 0.949 & 1.017 \\
\hline 9 & -1 & -1 & -1 & +1 & 30 & 20 & 150 & 160 & 1.456 & 1.431 \\
\hline 10 & +1 & -1 & -1 & +1 & 70 & 20 & 150 & 160 & 1.148 & 1.156 \\
\hline 11 & -1 & +1 & -1 & +1 & 30 & 26 & 150 & 160 & 1.078 & 1.033 \\
\hline 12 & +1 & +1 & -1 & +1 & 70 & 26 & 150 & 160 & 0.827 & 0.857 \\
\hline 13 & -1 & -1 & +1 & +1 & 30 & 20 & 210 & 160 & 1.457 & 1.326 \\
\hline 14 & +1 & -1 & +1 & +1 & 70 & 20 & 210 & 160 & 1.016 & 1.049 \\
\hline 15 & -1 & +1 & +1 & +1 & 30 & 26 & 210 & 160 & 0.966 & 1.090 \\
\hline 16 & +1 & +1 & +1 & +1 & 70 & 26 & 210 & 160 & 1.009 & 0.912 \\
\hline 17 & -2.0 & 0 & 0 & 0 & 10 & 23 & 180 & 150 & 1.549 & 1.605 \\
\hline 18 & +2.0 & 0 & 0 & 0 & 90 & 23 & 180 & 150 & 0.871 & 0.876 \\
\hline 19 & 0 & -2.0 & 0 & 0 & 50 & 17 & 180 & 150 & 1.292 & 1.386 \\
\hline 20 & 0 & +2.0 & 0 & 0 & 50 & 29 & 180 & 150 & 1.025 & 0.992 \\
\hline 21 & 0 & 0 & -2.0 & 0 & 50 & 23 & 120 & 150 & 1.053 & 1.064 \\
\hline 22 & 0 & 0 & +2.0 & 0 & 50 & 23 & 240 & 150 & 1.007 & 1.056 \\
\hline 23 & 0 & 0 & 0 & -2.0 & 50 & 23 & 180 & 130 & 1.354 & 1.393 \\
\hline 24 & 0 & 0 & 0 & +2.0 & 50 & 23 & 180 & 170 & 1.069 & 1.090 \\
\hline 25 & 0 & 0 & 0 & 0 & 50 & 23 & 180 & 150 & 1.158 & 1.109 \\
\hline 26 & 0 & 0 & 0 & 0 & 50 & 23 & 180 & 150 & 1.041 & 1.109 \\
\hline 27 & 0 & 0 & 0 & 0 & 50 & 23 & 180 & 150 & 1.104 & 1.109 \\
\hline 28 & 0 & 0 & 0 & 0 & 50 & 23 & 180 & 150 & 1.111 & 1.109 \\
\hline 29 & 0 & 0 & 0 & 0 & 50 & 23 & 180 & 150 & 1.132 & 1.109 \\
\hline
\end{tabular}

$X_{1}$ - apple pomace content in the mixture $\left(C_{p o m}, \%\right), X_{2}$ - moisture content $(W, \%), X_{3}$ - screw speed $(n, \mathrm{rpm}), X_{4}$ - barrel temperature $\left(T_{m},{ }^{\circ} \mathrm{C}\right)$

Table 2

Regression equation coefficients and analysis of variance for SEI of extruded 
Resource and Energy Saving Technologies of Production and Packing of Food Products as the Main Fundamentals of Their Competitiveness: Proceedings of the 8th International Specialized Scientific and Practical Conference, September 12, 2019. Kyiv, Ukraine

\section{apple pomace - wheat semolina mixtures}

\begin{tabular}{|c|c|c|c|c|}
\hline Variables & Coefficients & $\boldsymbol{D F}$ & $\boldsymbol{M S}$ & $\boldsymbol{p}$ values \\
\hline Constant & 1178.66 & & & \\
\hline$X_{1}$ & -7.84333 & 1 & 7971.62 & $0.0000^{*}$ \\
\hline$X_{2}$ & -5.94505 & 1 & 2324.6 & $0.0001^{*}$ \\
\hline$X_{3}$ & -0.03814 & 1 & 1.04167 & 0.9055 \\
\hline$X_{4}$ & -9.09125 & 1 & 1380.17 & $0.0006^{*}$ \\
\hline$X_{1} X_{1}$ & 0.00818 & 1 & 278.145 & 0.0683 \\
\hline$X_{2} X_{2}$ & 0.22074 & 1 & 102.405 & 0.2506 \\
\hline$X_{3} X_{3}$ & -0.00136 & 1 & 38.9881 & 0.4718 \\
\hline$X_{4} X_{4}$ & 0.03312 & 1 & 284.553 & 0.0655 \\
\hline$X_{1} X_{2}$ & 0.04146 & 1 & 99.0025 & 0.2583 \\
\hline$X_{1} X_{3}$ & -0.00008 & 1 & 0.04 & 0.9814 \\
\hline$X_{1} X_{4}$ & 0.0345 & 1 & 761.76 & $0.0056^{*}$ \\
\hline$X_{2} X_{3}$ & 0.04514 & 1 & 264.063 & 0.0748 \\
\hline$X_{2} X_{4}$ & -0.11792 & 1 & 200.222 & 0.1159 \\
\hline$X_{3} X_{4}$ & -0.00342 & 1 & 16.81 & 0.6348 \\
\hline
\end{tabular}

*Significant at $95 \%$ confidence level, $D F$ - degrees of freedom, $M S$ - mean square

Standardized Pareto Chart for SEI

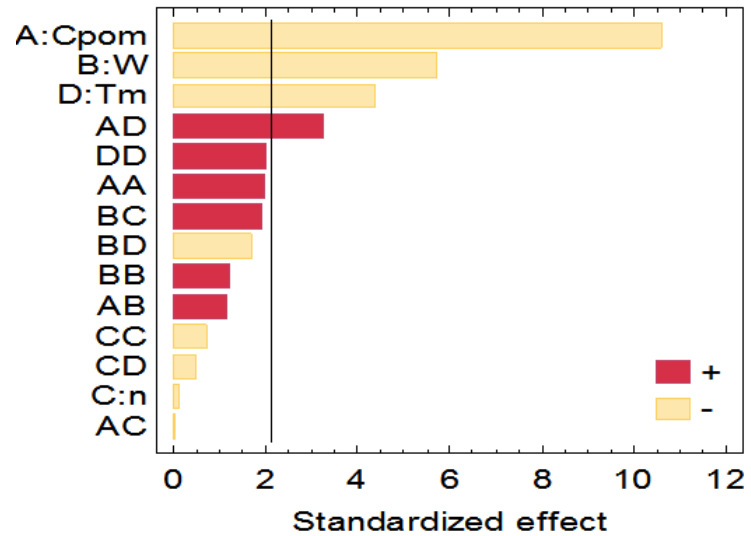

Figure 1. Estimated effects of regression model coefficients on SEI

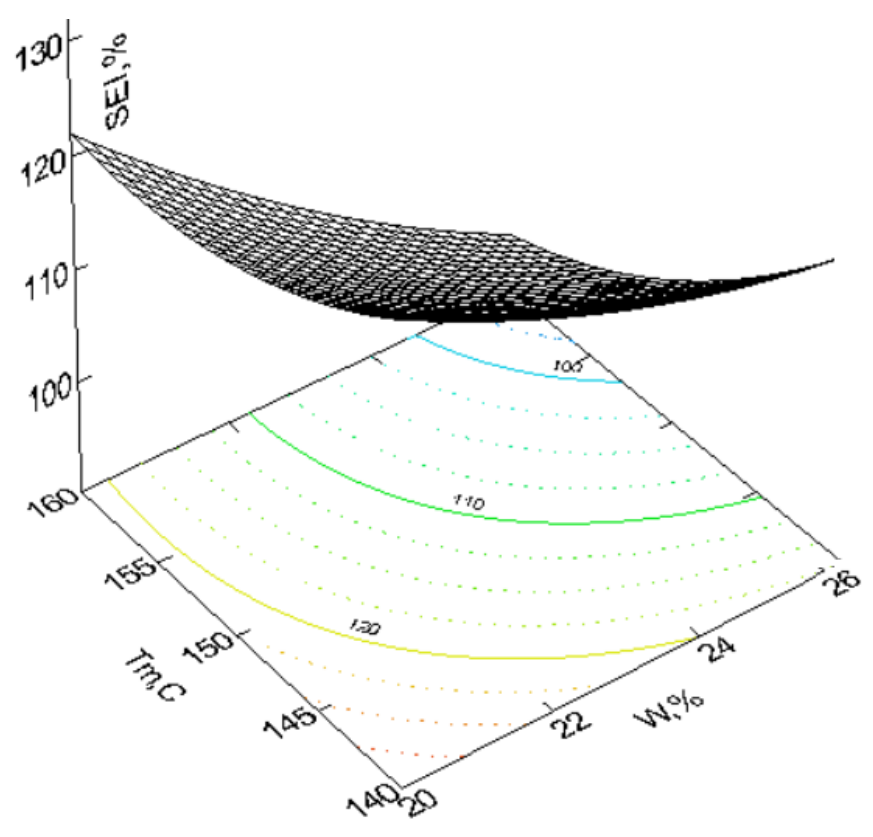

Figure 2. SEI (\%) depending on $\mathrm{T}_{\mathrm{m}}\left({ }^{\circ} \mathrm{C}\right)$ and $\mathrm{W}(\%)$ at $\mathrm{C}_{\mathrm{pom}}=\mathbf{5 0 \%}$ and $\mathrm{n}=180 \mathrm{rpm}$ 


\section{Conclusion}

The average $S E I$ values ranged from 0.827 to 1.637 . Statistical analysis showed that the apple pomace content in the mixture had the highest effect on the expansion. The moisture content and barrel temperature also affected SEI while screw speed had not affect expansion index of the extrudates.

\section{References}

1. Sudha M., Baskaran V., Leelavathi K. (2007), Apple pomace as a source of dietary fiber and polyphenols and its effect on the rheological characteristics and cake making, Food Chemistry, 104, pp. 686-692.

2. Reis S., Rai D., Abu-Ghannam N. (2012), Apple pomace as a potential ingredient for the development of new functional foods, International Conference on Food Safety, Quality and Nutrition, Manchester, UK, pp. 61-66.

3. Launay B., Lisch L. (1983), Twin-screw extrusion cooking of starches: Flow behaviour of starch pastes, expansion and mechanical properties of extrudates, Journal of Food Engineering, 52, pp. 1746-1747.

4. Guy R. (2001), Extrusion cooking - Technologies and applications, Woodhead Publishing Limited, Cambridge, England, 206 p.

5. Alvarez-Martinez L., Kondury K., Harper J. (1988), A general model for expansion of extruded products, Journal of Food Science, 53, pp. 609-615.

6. Fan J., Mitchell J., Blanshard J. (1996), The effect of sugars on the extrusion of maize grits: I. The role of the glass transition in determining product density and shape, International Journal of Food Science and Technology, 31, pp. 55-65.

7. Haber A., Runyon R. (1977), General Statistics. 3rd ed., Addison-Wesley Publishing Company, Reading, MA, 343 p.

8. Yağci S., Göğüş F. (2008), Response surface methodology for evalution of physical and functional properties of extruded snack foods developed from foodby-products, Journal of food engineering, 86 (1), pp. 122-132.

9. Yanniotis S., Petraki A., Soumpasi E. (2007), Effect of pectin and wheat fibers on quality attributes of extruded corn starch, Journal of Food Engineering, 80, pp. 594-599.

10. Ding Q., Ainsworth P., Plunkett A., Tucker G., Marson H. (2006), The Effect of Extrusion Conditions on the Functional and Physical Properties of Wheat-Based Expanded Snacks, Journal of Food Engineering, 73, pp. 142-148.

11. Kokini J., Lai L., Chedid L. (1992), Effect of starch structure on starch rheological properties, Food Technology, 46, pp. 124-139.

12. Gujska E., Khan K. (1990), Effect of temperature on properties of extrudates from high starch fractions of navy, pinto and garbanzo beans, Journal of Food Science, 55, pp. 466-469. 